\title{
Oxygen-limited thermal tolerance in Antarctic fish investigated by MRI and ${ }^{31} \mathrm{P}-\mathrm{MRS}$
}

\author{
F. C. MARK, C. BOCK, AND H. O. PÖRTNER \\ Alfred-Wegener-Institut für Polar- und Meeresforschung, \\ Ökophysiologie, D-27515 Bremerhaven, Germany
}

Received 15 March 2002; accepted in final form 31 July 2002

Mark, F. C., C. Bock, and H. O. Pörtner. Oxygen limited thermal tolerance in Antarctic fish investigated by MRI and ${ }^{31}$ P-MRS. Am J Physiol Regul Integr Comp Physiol 283: R1254-R1262, 2002. First published August 8, 2002; 10.1152/ajpregu.00167.2002.-The hypothesis of an oxygenlimited thermal tolerance was tested in the Antarctic teleost Pachycara brachycephalum. With the use of flow-through respirometry, in vivo ${ }^{31} \mathrm{P}-\mathrm{NMR}$ spectroscopy, and MRI, we studied energy metabolism, intracellular $\mathrm{pH}\left(\mathrm{pH}_{\mathrm{i}}\right)$, blood flow, and oxygenation between 0 and $13^{\circ} \mathrm{C}$ under normoxia $\left(\mathrm{PO}_{2}: 20.3\right.$ to $\left.21.3 \mathrm{kPa}\right)$ and hyperoxia $\left(\mathrm{PO}_{2}: 45 \mathrm{kPa}\right)$. Hyperoxia reduced the metabolic increment and the rise in arterial blood flow observed under normoxia. The normoxic increase of blood flow leveled off beyond $7^{\circ} \mathrm{C}$, indicating a cardiovascular capacity limitation. Ventilatory effort displayed an exponential rise in both groups. In the liver, blood oxygenation increased, whereas in white muscle it remained unaltered (normoxia) or declined (hyperoxia). In both groups, the slope of $\mathrm{pH}_{\mathrm{i}}$ changes followed the alpha-stat pattern below $6^{\circ} \mathrm{C}$, whereas it decreased above. In conclusion, aerobic scope declines around $6^{\circ} \mathrm{C}$ under normoxia, marking the pejus temperature. By reducing circulatory costs, hyperoxia improves aerobic scope but is unable to shift the breakpoint in $\mathrm{pH}$ regulation or lethal limits. Hyperoxia appears beneficial at sublethal temperatures, but no longer beyond when cellular or molecular functions become disturbed.

aerobic scope; heat stress; thermal tolerance limits; magnetic resonance imaging; magnetic resonance spectroscopy

FISH AND INVERTEBRATES endemic to the Antarctic Ocean live in a physically very stable and well-defined environment. Very low temperatures between -1.9 and $+1^{\circ} \mathrm{C}$ and excellent oxygen availability at low metabolic rates have led to physiological features that reflect adaptation to the permanent cold. To reduce blood viscosity, most Antarctic fish hold only low numbers (7) or are completely devoid [Channichthyidae (6)] of red blood cells. High levels of lipid and mitochondrial numbers result in improved oxygen diffusion and shorter cytosolic diffusion distances $(42,43)$. As a consequence of the high degree of cold temperature specialization, Antarctic fish are greatly restricted in their biogeographic distribution and are strongly confined to their environment, indicated by a low tolerance to heat (44).

Address for reprint requests and other correspondence: H. O. Pörtner, Alfred-Wegener-Institut für Polar- und Meeresforschung, Ökophysiologie, Postfach 1201 61, D-27515 Bremerhaven, F.R.G. (E-mail: hpoertner@awi-bremerhaven.de).
Stenothermality therefore appears to be the direct consequence of being highly adapted to the extreme environmental conditions of the Southern Ocean (34). However, the physiological mechanisms limiting thermal tolerance are still under dispute and several models of temperature tolerance have been introduced $(47,52)$.

On the basis of Shelford's law of tolerance (41), the recent work of Zielinski and Pörtner (57), Sommer et al. (45), van Dijk et al. (50), and Frederich and Pörtner (11) led to the concept of an oxygen-limited thermal tolerance. As most clearly visible in the spider crab Maja squinado (11), limits of thermal tolerance during both heating and cooling are indicated by a set of low and high pejus temperatures $\left(\mathrm{T}_{\mathrm{p}}\right) . \mathrm{T}_{\mathrm{p}} \mathrm{s}$ denote the beginning of decreased oxygen supply to an organism resulting in a drop in its aerobic scope and hence a reduction of scopes for activity, and possibly for growth and reproduction. In the pejus range between $\mathrm{T}_{\mathrm{p}}$ and the critical temperature $\mathrm{T}_{\mathrm{c}}$, animals still can survive, but only under the above mentioned restrictions until $\mathrm{T}_{\mathrm{c}}$ is reached, characterized by the onset of anaerobic metabolism (for review, see Ref. 29). In ecological terms, $\mathrm{T}_{\mathrm{p}}$ is therefore of great importance, as it may be found close to the temperature limits of biogeographical distribution.

It is hence conceivable that thermal tolerance limits relate to the loss of balance between $\mathrm{O}_{2}$ demand and supply. On the warm side, for instance, high mitochondrial densities as found in Antarctic species may result in greater energy losses due to proton leak $(15,33,34)$, which, with rising temperature, would soon lead to a situation in which oxygen demand surpassed oxygen availability. Limited oxygen availability to tissues might be the first manifestation of thermal intolerance and lead to lower optimum temperatures (35) before heat-induced damage at lower levels of complexity, i.e., organ or cellular functions, contributes to heat death of an animal $(29,30)$.

As a contribution to an understanding of the physiological basis of temperature-dependent biogeography in the light of global warming, we tested the hypothesis that oxygen limitation is the first line in a hierarchy of thermal tolerance limits in Antarctic fish (29). The key

The costs of publication of this article were defrayed in part by the payment of page charges. The article must therefore be hereby marked "advertisement" in accordance with 18 U.S.C. Section 1734 solely to indicate this fact. 
question is whether additional oxygen has a significant impact on thermal tolerance and how such an effect may become visible. In the context of earlier findings of $\mathrm{T}_{\mathrm{c}} \mathrm{S}$ in temperate and Antarctic zoarcids, Zoarces viviparus and Pachycara brachycephalum (50), we chose the Antarctic eelpout Pachycara brachycephalum as an experimental animal. Members of the fish family Zoarcidae are cosmopolitan and thus constitute good model organisms for a comparison of Antarctic fish to closely related species from temperate waters.

\section{MATERIAL AND METHODS}

Animals. Antarctic eelpouts (Pachycara brachycephalum) were caught in March 2000 near Deception Island (Antarctica) using baited traps at a depth of $475 \mathrm{~m}$. Water temperature was $0.4^{\circ} \mathrm{C}$ at a salinity of $34.5 \%$. Fish were $24-30 \mathrm{~cm}$ in size and weighed 36-74 g. Until the start of the experiments in June 2000, the fish were kept in aquaria onboard RV Polarstern and at the Alfred Wegener Institute (Bremerhaven) at ambient temperatures of $0 \pm 0.5^{\circ} \mathrm{C}$ and a salinity of $32.5 \%$. Fish were fed fresh shrimp ad libitum fortnightly and starved 8 days before experimentation to ensure that standard metabolic rate (SMR) was measured. Experiments were carried out between June and November 2000.

Experimental protocol. Experiments were conducted using a 4.7-T magnet with a 40-cm horizontal wide bore and actively shielded gradient coils (Bruker Biospec 47/40 DBX System). Inside the magnet, nonanesthetized animals were placed in a cylindrical flow-through Perspex chamber (Rietzel) of $\sim 300 \mathrm{ml}$ vol (15-cm long, $7-\mathrm{cm}$ wide, and $6 \mathrm{~cm}$ in height), in which they could move without restraint (Fig. 1). The fish remained inside the magnet throughout the whole experiment (for up to 9 days). A $5 \mathrm{~cm}^{1} \mathrm{H}_{-}{ }^{31} \mathrm{P}-{ }^{13} \mathrm{C}$ surface coil, directly placed under the animal chamber, was used for excitation and signal reception. To monitor temperature and oxygen concentration of in- and outflowing water, fluoroptic temperature (Polytec) and oxygen sensors (Comte) were installed directly upstream and downstream of the animal chamber inside the magnet. Seawater was supplied to the chamber hydrostatically out of a 50-liter reservoir, the temperature of which could be controlled to $\pm 0.1^{\circ} \mathrm{C}$ by means of cryostats (Lauda). Water flow could be controlled to $\pm 1 \mathrm{ml}$ between 2 and $500 \mathrm{ml} / \mathrm{min} . \mathrm{Po}_{2}$ in the reservoir was adjusted by a gas-mixing pump (Wösthoff).

Two experimental series were carried out, one under normoxia $\left(\mathrm{Po}_{2}: 20.3-21.3 \mathrm{kPa}\right)$ and one under hyperoxia $\left(\mathrm{PO}_{2}: 45\right.$ $\mathrm{kPa}$ ). Temperature in both series was increased between 0 and $15^{\circ} \mathrm{C}$ by $1{ }^{\circ} \mathrm{C} / 12 \mathrm{~h}$. Before experimentation, fish were left inside the experimental setup for at least $24 \mathrm{~h}$ to recover from handling stress, as evidenced from control ${ }^{31} \mathrm{P}-\mathrm{NMR}$ spectra. Respiration measurements were carried out during a 3-h period before each increase in temperature. Here, the water flow through the animal chamber was reduced from 300 to 3 $\mathrm{ml} / \mathrm{min}$ (depending on animal size and temperature), such that the animals depleted oxygen concentrations by $10-15 \%$. Experiments under normoxia and hyperoxia were carried out alternately to smooth out potential effects of aquarium captivity on oxygen consumption $\left(\mathrm{MO}_{2}\right)(39)$. In vivo ${ }^{31} \mathrm{P}-\mathrm{NMR}$ spectra [sweep width: $5,000 \mathrm{~Hz}$; flip angle: $45^{\circ}$ (pulse shape: bp 32; pulse length $100 \mu \mathrm{s}$ ); repetition time (TR): $1.0 \mathrm{~s} ; 600$ scans; duration: $10 \mathrm{~min}$; size: 4 kilobytes] were acquired continuously throughout the whole experiment to measure $\mathrm{pH}_{\mathrm{i}}$ and its changes represented by the position of the signal of $\mathrm{P}_{\mathrm{i}}$, relative to phosphocreatine ( $\mathrm{PCr}$ ) as an internal standard. The spectra were corrected for temperature and intracellular ion concentrations of marine organisms according to Ref. 4.

Alternating with spectroscopy, a flow-weighted MR imaging method (Fig. 1) was applied to examine blood flow in the Aorta dorsalis [similar to Ref. 3, using the following parameters: matrix, $128 \times 128$; field of view, $4 \times 4 \mathrm{~cm}$; 5 slices at 2 $\mathrm{mm}$ each; sweep width, $50,000 \mathrm{~Hz}$; flip angle, $45^{\circ}$ (using a hermite pulse of 2,000 $\mu \mathrm{s}$ ); TR, $100 \mathrm{~ms}$; echo time (TE), $10 \mathrm{~ms}$; acquisition time, $1 \mathrm{~min} ; 2$ averages]. In the images obtained, blood vessels were picked manually and changes in the ratio of signal intensity over noise intensity were used to determine relative changes in blood flow. To correct for movements of the fish inside the chamber, the position of the animal in relation to the excitation profile of the surface coil was taken

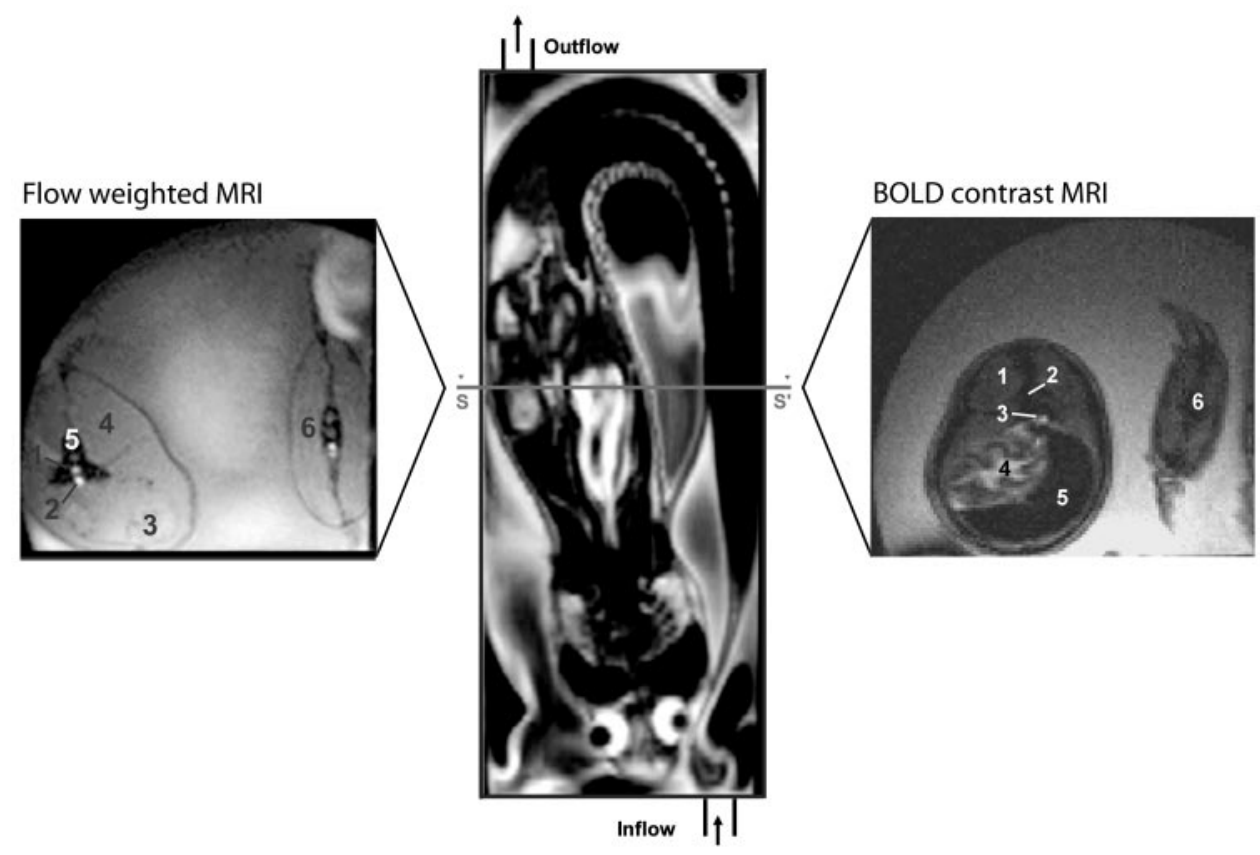

Fig. 1. Schematic view of a specimen of $P$. brachycephalum inside the experimental chamber (adapted from Ref. 4). Left: a typical flow-weighted MR image is depicted, its orientation indicated by the line ( $\left.\mathbf{S}^{-} \mathrm{S}^{\prime}\right)$ crossing the animal's trunk region (1, aorta dorsalis; 2 , vena cava posterior; 3 , stomach; 4 , dorsal muscle; 5 , spine; 6 , tail). Right: a $\mathrm{T}_{2}{ }^{*}$ weighted MR image [blood oxygenation level dependent (BOLD)] of the same anatomic position (1, dorsal white muscle; 2 , spine; 3 , blood vessels; 4, stomach; 5, liver; 6 , tail). 
into account. For better comparability of the data obtained from different fish, baseline corrections were applied to individual data. Signal intensities of regions of interest (ROI) in the fish were put in proportion to those of ROIs of the same position in a blank image.

To monitor oxygen supply to white muscle and liver, we applied a $\mathrm{T}_{2} *$ weighted gradient echo MR sequence for blood oxygenation level-dependent (BOLD) contrast MRI (27) [matrix, $128 \times 128$; field of view, $4 \times 4 \mathrm{~cm}$; 5 slices at $2 \mathrm{~mm}$ each; sweep width, 50,000 Hz; flip angle, $11^{\circ}$ (pulse shape, sinc3; pulse length 2,000 $\mu \mathrm{s}$ ); TR, $100 \mathrm{~s}$; TE, $40 \mathrm{~ms}$; acquisition time, 4 min; 4 repetitions; 2 averages]. In this method, the different magnetic properties of oxyhemoglobin (which is diamagnetic) and deoxyhemoglobin (paramagnetic) are used to account for changes within the ratio of oxy:deoxyhemoglobin and thus overall blood oxygenation level (Fig. 1).

In addition to the NMR experiments, a parallel experimental series was run with five animals kept in a 50-liter tank under normoxic and hyperoxic conditions, respectively. Temperature treatment was identical to the one described above. Respiration frequency was counted at each temperature and animals were filmed using a VHS video system for later analysis of the gill opercular width, carried out using the public domain NIH Image program (available at http://rsb. info.nih.gov/nih-image/). The product of ventilatory frequency and amplitude (i.e., opercular width) delivered a qualitative proxy for ventilatory effort.

Statistics. Data were examined for significant differences between normoxic and hyperoxic experimental series by a one-factorial analysis of covariance (ANCOVA) and a post hoc Student-Newman-Keuls test (Super ANOVA, Abacus Concepts); the level of significance was $P<0.05$. Within each experimental series, specific segments were compared by a paired sample contrasts analysis (Super ANOVA). Slopes were compared with one another using an $f$-test. Again, a $P<$ 0.05 was considered significant. Regressions and squared correlation coefficients were calculated using Sigma Plot 2000 (SPSS). All values are presented as means \pm SE.

\section{RESULTS}

As evidenced from control ${ }^{31} \mathrm{P}-\mathrm{NMR}$ spectra, handling stress elicited by the introduction of the fish into the setup resulted in a slight reduction of $\mathrm{PCr} / \mathrm{P}_{\mathrm{i}}$ ratios from which the fish recuperated within 1-2 h. For the remaining time of the control period and throughout the whole of the experiment, there was no detectable change in the levels of high-energy phosphates (data not shown), which is commonly accepted as a sign of animal well being $(4,26)$. As could be seen from MR imaging, fish remained calm and only rarely moved inside the animal containers (data not shown), similar to the behavior the fish show in our aquariums, where they tend to hide in narrow plastic tubes.

$\mathrm{Mo}_{2}$ under control conditions (normoxia, $0-1^{\circ} \mathrm{C}$ ) equivalent to standard metabolic rate (SMR) was in accordance with published data for Antarctic eelpouts $(50,53,55)$ and did not differ significantly from hyperoxic control $\mathrm{Mo}_{2}$. With rising temperature, $\mathrm{MO}_{2}$ of Pachycara brachycephalum followed a typical exponential function under normoxia (Fig. $2 B$ ). However, exposure to hyperoxia and warmer temperatures resulted in a more linear increase in $\mathrm{Mo}_{2}$, reflecting a strong reduction of the exponential increment observed under normoxic conditions. The two patterns of $\mathrm{Mo}_{2}$ differed significantly above $8^{\circ} \mathrm{C}$, from where the need for oxygen under normoxia increasingly exceeded the level of $\mathrm{Mo}_{2}$ under hyperoxia. The $\mathrm{Q}_{10}$ between 2 and $12^{\circ} \mathrm{C}$ was $3.40 \pm 0.55$ and $2.63 \pm 0.48$ for normoxia and hyperoxia, respectively (means $\pm \mathrm{SE}$ ).

These findings were also reflected in the blood flow through the main dorsal blood vessel (Aorta dorsalis) of the fish (Fig. 2C). Although blood flow generally seemed to increase with rising temperature under both normoxic and hyperoxic conditions, it was only under normoxia that it rose steadily up to $6^{\circ} \mathrm{C}$ and reached levels significantly higher than under control conditions (as indicated by the asterisks in Fig. $2 C$ ). During warming above $7^{\circ} \mathrm{C}$, no further increase in blood flow occurred. In contrast, blood flow under hyperoxia did not increase significantly, but remained fairly constant regardless of the temperature applied.

In both groups, the increase in ventilatory frequency was virtually identical over the range of temperatures, with a tendency toward a slightly lesser increment above $8^{\circ} \mathrm{C}$ under hyperoxia (data not shown). The same observation holds for ventilatory amplitude above $5^{\circ} \mathrm{C}$. Below $5^{\circ} \mathrm{C}$, opercular movement was too feeble under hyperoxia to be accurately measured $(<1 \mathrm{~mm})$, resulting in a significant difference between hyperoxia and normoxia below $5^{\circ} \mathrm{C}$ (data not shown). Ventilatory effort (Fig. 2A) hence showed an exponential incline with rising temperature slightly lower under hyperoxia (with a statistically significant difference in relation to normoxia only for 3 and $4^{\circ} \mathrm{C}$, however).

BOLD contrast in white muscle (Fig. $3 A$ ), depicting blood oxygenation levels, did not change significantly with increasing temperature under normoxia, although there was a slight trend of decreasing oxygenation at higher temperatures. In the hyperoxic series, BOLD contrast showed a pronounced decrease between 5 and $6^{\circ} \mathrm{C}$, with tissue oxygenation levels being significantly lower between 6 and $13^{\circ} \mathrm{C}$ than between 0 and $5^{\circ} \mathrm{C}$. In the liver, however, tissue oxygenation levels displayed a nonsignificant trend to increase with temperature in both experimental series. This trend was somewhat more pronounced under hyperoxia (Fig. 3B).

White muscle $\mathrm{pH}_{\mathrm{i}}$ under normoxia at $0^{\circ} \mathrm{C}$ was $7.41 \pm$ 0.02 , whereas $\mathrm{pH}_{\mathrm{i}}$ values in the hyperoxic group were somewhat higher at low temperatures (Fig. 4). We did not observe significant differences in temperature-dependent $\mathrm{pH}_{\mathrm{i}}$ changes between hyperoxia and normoxia. In both groups, $\mathrm{pH}_{\mathrm{i}}$ regulation followed a pattern close to the one predicted by the alpha-stat hypothesis, however, only below $6^{\circ} \mathrm{C}$. Whereas the hypothesis predicts that rising temperature should cause an acidification of $-0.017 \mathrm{pH}$ units $/{ }^{\circ} \mathrm{C}(36,37)$, we found a slope of $\Delta \mathrm{pH} /{ }^{\circ} \mathrm{C}$ of -0.012 units $\left(R^{2} 0.89\right)$ under normoxia and -0.015 units $/{ }^{\circ} \mathrm{C}\left(R^{2} 0.98\right)$ under hyperoxia, respectively. Above $6^{\circ} \mathrm{C}, \mathrm{pH}$ regulation followed a significantly different pattern with a $\Delta \mathrm{pH}$ of -0.004 units $/{ }^{\circ} \mathrm{C}\left(R^{2} 0.51\right)$ for the normoxic and -0.007 units $/{ }^{\circ} \mathrm{C}$ $\left(R^{2} 0.75\right)$ for the hyperoxic series. In general, the decrease of $\mathrm{pH}_{\mathrm{i}}$ with rising temperature appeared slightly 
larger under hyperoxia than under normoxia; however, the differences in slope were not significant.

All fish died around $13^{\circ} \mathrm{C}$, independent of the oxygen concentration. There was no obvious difference between hyperoxia and normoxia, possibly also due to the greater influence of interindividual variability on thermal tolerance compared with oxygen concentration. Shortly before death $(\sim 30 \mathrm{~min})$, there was a pronounced drop in white muscle $\mathrm{pH}_{\mathrm{i}}$. This was consistently observed in all the animals included in the study.

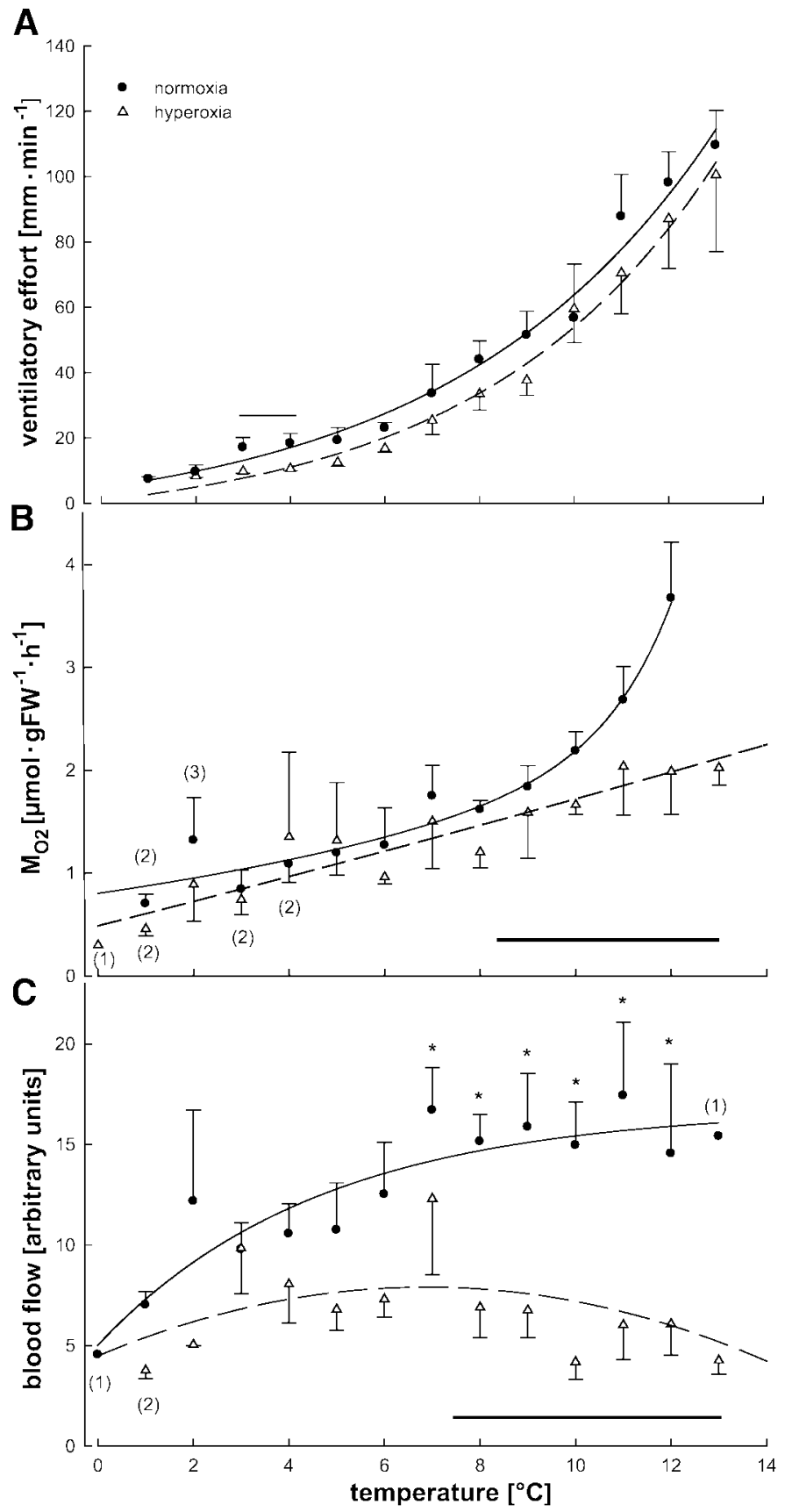

\section{DISCUSSION}

Oxygen and the cardiovascular and ventilatory systems. Fanta et al. (10) showed that ventilation frequencies of Antarctic fish (Notothenia sp., Trematomus sp.) decrease under hyperoxia, an effect that has been reported for various marine and freshwater fish species $(2,14)$. This stands in opposition to our observations in Pachycara brachycephalum, where ventilation frequency did not differ between normoxia and hyperoxia. Instead, ventilation amplitude was reduced under hyperoxia, although significantly only at slightly elevated habitat temperatures between 3 and $4^{\circ} \mathrm{C}$. Even though ventilation frequency might be lowered in some species and the $\mathrm{PO}_{2}$ difference between blood and water rises, it is commonly found that arterial $\mathrm{PO}_{2}$ rises in proportion to the $\mathrm{PO}_{2}$ of the medium under hyperoxia due to increased oxygen availability $(46,48,56) . \mathrm{O}_{2}$ can passively enter the blood via the gills and the skin; even under normoxia, up to $35 \%$ of the total amount of oxygen consumed at rest in the Antarctic eelpout Rhigophila dearborni can be attributed to cutaneous uptake (53). Hyperoxia thus alleviates the workload required for sufficient oxygen supply to tissues and at the same time increases the scope for active oxygen uptake and, in consequence, aerobic scope.

Because oxygen solubility is elevated at low temperatures, icefish (Channichthyidae) resort to $\mathrm{O}_{2}$ transport in solely physical solution and can afford to abandon the use of respiratory pigments like hemoglobin (6). Sluggish benthic zoarcids and nototheniids that still rely on hemoglobin only do so at very low hematocrit levels between 10 and $18 \%$ [P. brachycephalum: $13 \%$, personal observation; $R$. dearborni: $10.5 \pm 3.0 \%$ (53); Nototheniids: 10-18\% (7)], thus reducing blood viscosity, which again lowers the costs of blood circulation. At low temperatures, physically dissolved oxygen can constitute up to $30 \%$ of the total amount of blood oxygen and much of the improved $\mathrm{O}_{2}$ supply

Fig. 2. Ventilatory effort $(A)$, oxygen consumption $\left(B ; \mathrm{Mo}_{2}\right)$, and arterial blood flow in the Aorta dorsalis $(C)$ of $P$. brachycephalum under normoxia and hyperoxia with rising temperature. $A$ : ventilatory effort as the product of ventilatory frequency and amplitude. Effort increased exponentially with rising temperature in both groups. As indicated by the horizontal line, it was significantly lower under hyperoxia between 3 and $4^{\circ} \mathrm{C}(n=4$ or 5). Normoxia: $f=$ $(-6.94 \pm 7.64)+(11.69 \pm 4.68) \cdot \exp (0.18 \pm 0.03 \cdot x) ; R^{2}=0.98$. Нyperoxia: $f=(-7.40 \pm 5.89)+(8.29 \pm 3.09) \cdot \exp (0.20 \pm 0.03 \cdot x) ; R^{2}=$ 0.99. $B$ : as indicated by the horizontal line, $\mathrm{Mo}_{2}$ above $8^{\circ} \mathrm{C}$ was significantly different between normoxia and hyperoxia. Under normoxia, $\mathrm{MO}_{2}$ showed a large exponential increment, which could not be detected under hyperoxia $(n=3-7$ for the normoxic and $n=3-6$ for the hyperoxic series, unless indicated otherwise). Normoxia: $f=$ $(0.80 \pm 0.13) \cdot \exp (0.08 \pm 0.04 \cdot x)+(0.0002 \pm 0.0014) \cdot \exp (0.74 \pm$ $0.48 \cdot x) ; R^{2}=0.96$. Hyperoxia: $f=0.47+(0.13 \cdot x) ; R^{2}=0.99$. $C$ : arterial blood flow, as derived from flow-weighted MR images. Under normoxia, blood flow increased during warming to $7^{\circ} \mathrm{C}$, and it remained constant and significantly elevated above that temperature(depicted by *). Blood flow under hyperoxia remained fairly constant. The black line indicates the temperature area between 8 and $13^{\circ} \mathrm{C}$, in which blood flow differed significantly between both experimental series $(n=3-6$ for the normoxic and $n=4-6$ for the hyperoxic series, unless indicated otherwise). Line fits indicate an overall trend within the data sets. 


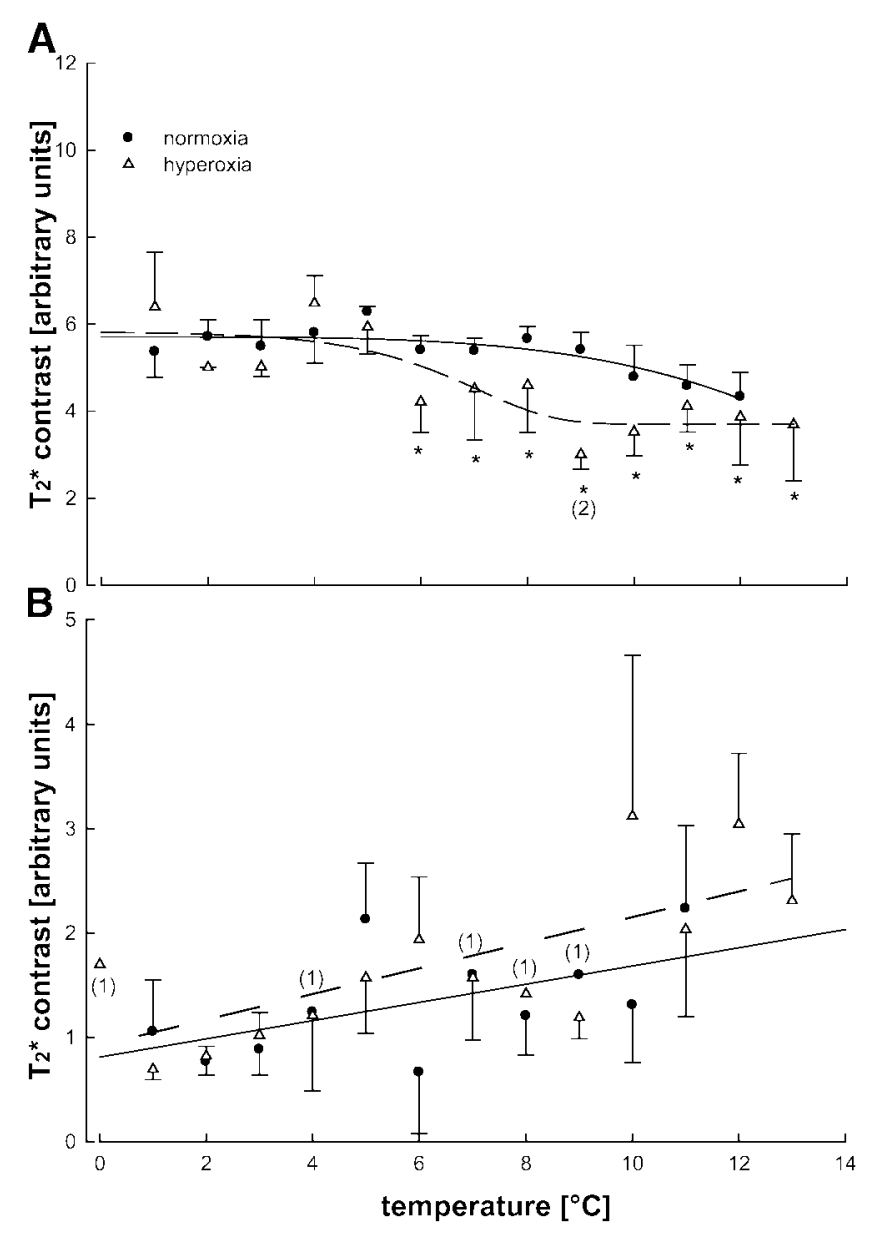

Fig. 3. White muscle $(A)$ and liver $(B)$ tissue oxygenation under normoxia and hyperoxia with rising temperature, as derived from BOLD contrast of $\mathrm{T}_{2}{ }^{*}$ weighted MR images. A: under normoxia, white muscle tissue oxygenation levels remained constant with rising temperature, whereas in the hyperoxic series oxygenation levels between 6 and $13^{\circ} \mathrm{C}$ were significantly lower than below $6^{\circ} \mathrm{C}(*)(n=$ 2 or 3 for the normoxic and $n=2-5$ for the hyperoxic series). Line fits indicate an overall trend within the data sets. $B$ : in both experimental series there was a trend in liver tissue oxygenation levels to increase with rising temperature. This trend appeared to be more pronounced under hyperoxia, although individual oscillations were large ( $n=2$ for the normoxic and $n=3-5$ for the hyperoxic series, unless indicated otherwise). Normoxia: $f=0.81+0.09 \cdot x ; R^{2}=0.32$. Hyperoxia: $f=0.85+0.13 \cdot x ; R^{2}=0.52$.

under hyperoxia occurs by enhancing the levels of physically dissolved oxygen.

Good oxygen availability and a stable, cold-stenothermal environment support low energy turnover lifestyles in Antarctic fish, not least via the reduction of the energy cost of cardiovascular and ventilatory work. If the capacity of ventilation and circulation is adjusted accordingly low, these fish become stenothermal, meaning that a temperature-induced rise in metabolic oxygen requirements cannot adequately be met by oxygen delivery through ventilation and the cardiovascular system. A decline in aerobic scope would therefore be the first consequence of thermal stress elicited by environmental warming.

Extending from earlier considerations by Jones (19), a decline in whole animal aerobic scope likely marks the temperature at which oxygen delivery capacities fall back behind the rising energy demand of cardiovascular and other aerobic tissues such as liver. Ventilatory and circulatory organs might therefore be among the first to be affected by progressive oxygen limitations, which in consequence lead to a vicious circle of an ever-increasing oxygen deficiency (11). While ventilation and blood circulation are sped up to augment oxygen supply, ventilatory and especially circulatory musculature consume most of the delivered oxygen themselves, and thus only exacerbate the deficit by further increasing $\mathrm{Mo}_{2}$. Evidently, the cost of circulation explains much of the exponential rise in $\mathrm{MO}_{2}$ observed under normoxia (Figs. 2 and 3), which is frequently found in fish respiration experiments $(1,50$, $55)$. This is indirectly supported by observations by van Ginneken et al. (51), who found $\mathrm{Mo}_{2}$ to increase under hypoxia in tilapia (Oreochromis mossambicus). Starting from a fractional cost of $30 \%$ of SMR for ventilation and circulation in a resting fish (18), an increasing part of the SMR will have to be accredited to ventilation and especially circulation at high temperatures and thereby contribute to the loss in aerobic scope.

The increase and subsequent plateau in blood flow with rising temperature under normoxia indicate a cardiovascular capacity limitation above $7^{\circ} \mathrm{C}$, resulting in a mismatch in oxygen delivery and demand. This leads to a drop in aerobic scope, suggesting the $7^{\circ} \mathrm{C}$ threshold to be a $\mathrm{T}_{\mathrm{p}}$ (11), when blood flow becomes limited by the insufficient capacity of the heart to overcome frictional resistance within the vascular system. As under this situation of rising thermal stress fish cannot further upregulate hemoglobin oxygenation

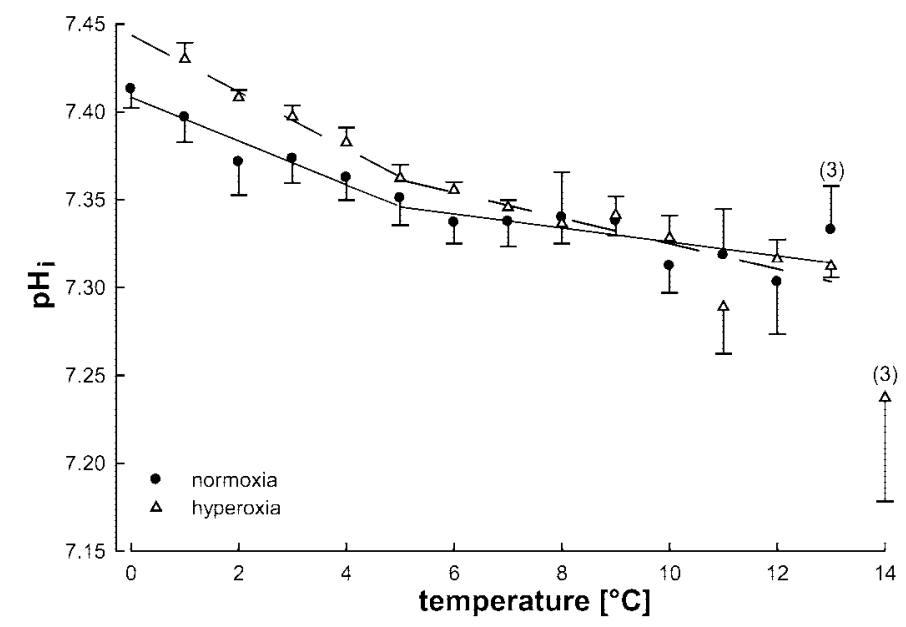

Fig. 4. White muscle intracellular $\mathrm{pH}\left(\mathrm{pH}_{\mathrm{i}}\right)$ values derived from in vivo ${ }^{31} \mathrm{P}-\mathrm{NMR}$ spectra of the Antarctic eelpout $P$. brachycephalum. At temperatures below $6^{\circ} \mathrm{C}, \mathrm{pH}_{\mathrm{i}}$ regulation in normoxic and hyperoxic animals followed an alpha-stat pattern with a $\Delta \mathrm{pH}$ of -0.012 units $/{ }^{\circ} \mathrm{C}\left(R^{2}=0.89\right)$ for the normoxic and -0.015 units $/{ }^{\circ} \mathrm{C}\left(R^{2}=0.98\right)$ for the hyperoxic experimental series, respectively. Beyond $6^{\circ} \mathrm{C}, \Delta \mathrm{pH}$ was -0.004 units $/{ }^{\circ} \mathrm{C}\left(R^{2}=0,51\right)$ for the normoxic and -0.007 units $/{ }^{\circ} \mathrm{C}\left(R^{2}=0.75\right)$ for the hyperoxic series, indicating a different pattern of $\mathrm{pH}$ regulation. In both cases, the increment of the function below $6^{\circ} \mathrm{C}$ was significantly different from the slope above $6^{\circ} \mathrm{C}(n=$ $5-7$ for the normoxic and $n=4$ or 5 for the hyperoxic series, unless indicated otherwise). 
or blood $\mathrm{PO}_{2}$ levels, oxygen extraction (i.e., $\Delta \mathrm{Po}_{2}$ between arterial and venous $\mathrm{Po}_{2} \mathrm{~S}$ ) is increased to meet the rising requirements for oxygen. Venous $\mathrm{PO}_{2}$ drops, reflecting a worsening of oxygen supply to the heart in fish, as pointed out by Pörtner et al. (31) for the cod, Gadus morhua. Finally, a $\mathrm{T}_{\mathrm{c}}$ is reached, which by definition (57) marks the onset of anaerobic metabolism and complete loss of aerobic scope (see Ref. 29). Our data set, however, which focused on an evaluation of $T_{p} s$, is not suitable to identify a distinct $T_{c}$. Van Dijk et al. (50) chose succinate in liver tissue as a reliable indicator of $\mathrm{T}_{\mathrm{c}}$ in their experiments on P. brachycephalum, which were carried out onboard RV Polarstern shortly after animal capture. The authors found $\mathrm{T}_{\mathrm{c}}$ to be situated around $9^{\circ} \mathrm{C}$, which was the same temperature at which $\mathrm{Mo}_{2}$ was maximal. At this temperature, the animals lost balance and died. In our study, these processes likely occurred $\sim 13^{\circ} \mathrm{C}$. This indicates that stress levels in the animals might have been higher in van Dijk's experiments than in ours, owing to the nature of experimental conditions onboard the research vessel.

The data obtained under hyperoxia indicate that additional oxygen can lower cardiovascular costs and thereby overall $\mathrm{Mo}_{2}$. This perception is strongly supported by the blood flow data (Fig. 2, $B$ and $C$ ). While under normoxia, blood flow gradually increased until it reached a steady level above $7^{\circ} \mathrm{C}$; it remained fairly constant under hyperoxia after a small increment between 1 and $4^{\circ} \mathrm{C}$. In consequence, circulation did not breach the line above which it became counterproductive, i.e., consuming more oxygen than it could deliver. It can therefore be expected that under hyperoxia, $\mathrm{Mo}_{2}$ would display a more prolonged exponential phase and should support survival at higher temperatures than under normoxia. These findings are in accordance with a suggested hierarchy of thermal tolerance, where reduction in aerobic scope is the "first line of sensitivity" affected by thermal stress, giving way to the next set of limiting factors $(29,30)$. These factors are thus far unexplained in the eelpout but lead to death at $\sim 13^{\circ} \mathrm{C}$. Reduced $\mathrm{O}_{2}$ demand and blood flow under hyperoxia at elevated temperatures suggest an enhanced functional reserve to the animal. This reflects an enhanced aerobic scope or upward shift in $\mathrm{T}_{\mathrm{p}}$, which must be considered significant. Yet a beneficial effect of $\mathrm{O}_{2}$ on $\mathrm{T}_{\mathrm{c}}$ is not clear, likely because $\mathrm{T}_{\mathrm{c}}$ and, furthermore, molecular limits, coincide.

Tissue oxygenation. For further support of the above conclusions we monitored tissue oxygenation changes in white muscle and liver by applying BOLD imaging. However, various physiological and physical effects can differentially influence BOLD contrast. Only with adequate consideration of these effects will interpretation of these data become possible. Physiologically, BOLD contrast reflects the ratio of oxy- and deoxyhemoglobin, which depends on $\mathrm{PO}_{2}$ and temperature, as well as Bohr and Root effects. The latter can be excluded in sedentary and benthic Antarctic fish (54), whereas the former would contribute to a drop in BOLD contrast during a potential heat-induced extra- cellular acidosis. This appears unlikely to explain the drop in BOLD contrast during hyperoxia compared with normoxia, as such a metabolic acidosis would be more severe during normoxia. A change in hematocrit can influence signal baseline as well (24) and evoke a rise in BOLD contrast regardless of the tissue, in line with a rise in hemoglobin-borne oxygen. Antarctic notothenioid teleosts are theoretically able to enhance hematocrit via release of sequestered erythrocytes from the spleen (9); it is unknown whether this occurs in zoarcids. Again, this predicted pattern contradicts the drop in BOLD contrast observed in white muscle, especially during hyperoxia vs. normoxia and thus appears unlikely. Finally, tissue perfusion rates are positively correlated with BOLD contrast (21) and the ratio of metabolic rate over blood flow $\left(\mathrm{MRo}_{2} / \mathrm{BF}\right)$ is negatively correlated to $R_{2}{ }^{*}\left(1 / \mathrm{T}_{2}{ }^{*}\right)$, as recently shown for brain by Hyder et al. (17). Thus a rise in tissue perfusion would lead to a rise in BOLD contrast, similar to a rise in hemoglobin oxygenation. On the physical side, in relying on $\mathrm{T}_{2}{ }^{*}$ weighted $\mathrm{MR}$ imaging, BOLD contrast is strongly influenced by $\mathrm{T}_{2}$, local inhomogeneities of the magnetic field (22), dissolved molecular oxygen $(20,28)$, and other paramagnetic ions and molecules, all of which elicit a decrease in BOLD contrast. Especially liver tissue is known for its low $\mathrm{T}_{1}$ and $\mathrm{T}_{2}$ values due to its dense matrix and high concentrations of paramagnetic ions (25), and BOLD contrast changes may thus appear more pronounced in this tissue compared with other tissues with the same change in oxygenation.

Nonetheless, Lebon et al. (23) and Semple et al. (40) have shown for both human muscle and liver tissue that changes in $\mathrm{T}_{2}{ }^{*}$ weighted MR images can be attributed to changes in blood oxygenation levels. Overall, application of BOLD contrast techniques should constitute a helpful in vivo tool to at least qualify if not quantify tissue oxygenation changes.

In the present study, field homogeneity was good (Fig. 1) and no differences between BOLD contrast under normoxia and hyperoxia were observed at control temperatures. Environmental hyperoxia is hence not likely to directly influence tissue oxygenation levels, as a consequence of reduced blood flow and ventilation rate (18). Despite increased $\mathrm{O}_{2}$ demand during normoxic warming, blood oxygen levels in muscle tissue (Fig. 3A) remained constant throughout the experiments. Maintenance of aerobic scope at increased $\mathrm{SMR}$ would require a rise in blood $\mathrm{PO}_{2}$ to maintain the balance between demand and supply. A moderate drop in $\mathrm{PO}_{2}$ may in fact occur, concealed by the maintenance of $\mathrm{T}_{2}{ }^{*}$, owing to the flow dependence of BOLD contrast. As a corollary, the maintenance or fall of blood $\mathrm{Po}_{2}$ in the light of increased organismic and cellular oxygen demand and blood flow indicates less aerobic flexibility.

Interestingly, we found a significant decline in muscle oxygenation above $5^{\circ} \mathrm{C}$ under hyperoxia, starting from $\mathrm{O}_{2}$ levels similar to those under normoxia. The reduction in blood oxygenation evidently was not compensated for by an increase in blood flow. Even if a significant effect of blood flow on BOLD contrast oc- 
curs, these interpretations hold. The lower levels of blood flow under hyperoxia (Fig. $2 C$ ) likely cause the decrease in blood oxygenation in the muscle tissue and reflect the lower whole animal $\mathrm{O}_{2}$ demand.

When measuring white muscle tissue $\mathrm{PO}_{2}$ invasively with microelectrodes, Fanta et al. (10) found decreasing muscle oxygenation under hyperoxia in one notothenioid species. However, even within the same genus, this was not a general response to elevated oxygen levels. It thus needs to be emphasized that blood oxygenation in white muscle, which is metabolically relatively inactive at rest, does not reflect oxygen supply to central aerobic organs such as the liver. Here (Fig. $3 B$ ) we found that tissue oxygenation was inclined to increase with rising temperature, a trend slightly more prominent under hyperoxia than under normoxia. It is conceivable that visceral blood oxygenation levels increase during warming to meet rising metabolic oxygen demands (8), this possibly being a trade-off at the expense of reduced blood supply to the less active muscular tissue (18). At unchanged levels of blood flow, this scheme might be more pronounced under hyperoxia. Moreover, as a consequence of the relatively low signal intensity in liver tissue (see above), any changes in BOLD contrast will appear more dramatic than, for instance, in muscle tissue. In conclusion, our data imply that oxygenation levels can be increased or remain unchanged in more vital organs such as liver when oxygen supply to muscle is reduced.

$p H_{i}$ regulation. Initial values of white muscle $\mathrm{pH}_{\mathrm{i}}$ under normoxia at $0^{\circ} \mathrm{C}(7.41 \pm 0.02)$ were very similar to the $7.43 \pm 0.06$ obtained by Van Dijk et al. (50) using the homogenate method (32) and to the values found by Bock et al. (4) by NMR measurements in the same species at the same temperature. Hyperoxia-induced reduction of ventilatory effort at low ambient temperatures can evoke a respiratory acidosis, due to the accumulation of $\mathrm{CO}_{2}$ in the blood (14). This can be compensated for within 2-3 days by a subsequent active uptake of $\mathrm{HCO}_{3}^{-}$via the gill $\mathrm{HCO}_{3}^{-} / \mathrm{Cl}^{-}$exchanger $(5,16)$. Resulting elevated bicarbonate levels in the blood affect the mechanisms of $\mathrm{pH}_{\mathrm{i}}$ regulation, again most likely $\mathrm{HCO}_{3}^{-} / \mathrm{Cl}^{-}$exchangers and $\mathrm{HCO}_{3}^{-}$/ $\mathrm{Na}^{+}$cotransporters (12), thereby explaining the higher initial $\mathrm{pH}_{\mathrm{i}}$ values under hyperoxia.

Evidently, the decline in aerobic scope suggested to occur beyond $5-6^{\circ} \mathrm{C}$ parallels a shift in the pattern of temperature-dependent $\mathrm{pH}_{\mathrm{i}}$ regulation, indicated by the distinct break around $5^{\circ} \mathrm{C}$. The fact that this pattern remains more or less unchanged under hyperoxia leads to the conclusion that it matches the normoxic pejus threshold but is not influenced by oxygen availability. A possible cause for this shift in $\mathrm{pH}$ regulation might be in the thermal sensitivity of ion channels or a change in the relationship between membrane permeability and compensatory ion exchange. Thermal inactivation of ion transport (e.g., $\mathrm{Na}^{+} / \mathrm{H}^{+}, \mathrm{Cl}^{-} / \mathrm{HCO}_{3}^{-}$exchanger, $\mathrm{H}^{+}$-ATPase) is very likely not yet involved, owing to the steady-state nature of temperature-dependent $\mathrm{pH}_{\mathrm{i}}$ values reached. The slightly steeper slopes under hyperoxia may relate to the elevated blood bicarbonate levels but do not significantly shift the break temperature.

As pointed out by Sommer et al. (45), alpha-stat regulation of $\mathrm{pH}_{\mathrm{i}}$ in a marine invertebrate was restricted to a temperature window between the $\mathrm{T}_{\mathrm{c}}$ limits. The data obtained here for $P$. brachycephalum indicate that already the normoxic $\mathrm{T}_{\mathrm{p}}$ correlates with a shift in $\mathrm{pH}$ regulation. This is also consistent with the data provided by van Dijk et al. (50), who found a deviation from alpha-stat $\mathrm{pH}_{\mathrm{i}}$ regulation between 3 and $6^{\circ} \mathrm{C}$ in $P$. brachycephalum but located $\mathrm{T}_{\mathrm{c}}$ close to $9^{\circ} \mathrm{C}$ (see above). Overall, the parallel events in oxygen metabolism and acid-base regulation confirm previous applications of the symmorphosis concept (49) to the limits of thermal tolerance, i.e., that the functional properties and capacities of several physiological systems are set to be optimal between the highs and lows of ambient temperatures and may thus show limitations or changes at similar levels of ambient temperatures (30; see Ref. 38 for endotherms).

In conclusion, under normoxia, a putative reduction of the aerobic scope, which coincides with a break in $\mathrm{pH}$ regulation around $5^{\circ} \mathrm{C}$, can be made out between 6 and $7^{\circ} \mathrm{C}$ and is reflected in limited capacity of the circulatory system to enhance arterial blood flow. Our findings suggest that improved oxygen availability diminishes the effects of thermal stress by reducing the energy costs associated with oxygen distribution in the organism. High ambient oxygen levels will also help when oxygen demand is on the verge of exceeding oxygen availability as it is set by the functional capacity of the cardiocirculatory system. Although hyperoxia likely improves aerobic scope during thermal stress and may thereby widen the tolerance window delimited by the $\mathrm{T}_{\mathrm{p}} \mathrm{s}$, the temperature dependence of $\mathrm{pH}$ regulation remains largely unaffected, likely due to fixed thermal properties of membranes or ion exchange mechanisms. This indicates that once the oxygen limitation of thermal tolerance has been alleviated, as shown by the uniform pattern of arterial blood flow under hyperoxia, further restrictive mechanisms at cellular or molecular levels may become effective. In general, our findings confirm that in vertebrates several processes are responsible for setting thermal tolerance limits, all of which seem tightly intertwined. Further work is necessary to elucidate the factors that restrict temperature tolerance once oxygen limitation is suspended; these may be located on a lower functional, i.e., cellular level (30). Overall, the capacity of Antarctic fish to adapt to climate-induced temperature changes appears very small. Oxygen-limited windows of thermal tolerance are narrow in this group and reflect its high sensitivity to current and, possibly, future scenarios of warming in Antarctic waters (13).

We thank R. M. Wittig, who provided the excellent laboratory conditions for both conducting the NMR experiments as well as for data analysis. B. Klein provided and maintained the fish used in these experiments.

This work is a contribution to the ELOISE project: effects of climate-induced temperature change on marine coastal fishes (CLI- 
COFI), funded by the European Union program "Climate and environment," contract No. ENV4-CT97-0596.

\section{REFERENCES}

1. Beamish FWH. Respiration of fishes with special emphasis on standard oxygen consumption. II. Influence of weight and temperature on respiration of several species. Can $J$ Zool 42: 177188, 1964.

2. Berschick P, Bridges CR, and Grieshaber MK. The influence of hyperoxia, hypoxia and temperature on the respiratory physiology of the intertidal rockpool fish Gobius cobitis Pallas. $J$ Exp Biol 130: 369-387, 1987.

3. Bock C, Sartoris FJ, and Pörtner HO. In vivo MR spectroscopy and MR imaging on non-anaesthetized marine fish: techniques and first results. Magn Reson Imaging 20: 165-172, 2002.

4. Bock C, Sartoris FJ, Wittig RM, and Pörtner HO. Temperature-dependent $\mathrm{pH}$ regulation in stenothermal Antarctic and eurythermal temperate eelpout (Zoarcidae): an in-vivo NMR study. Polar Biol 24: 869-874, 2001.

5. Burleson ML and Smatresk NJ. Branchial chemoreceptors mediate ventilatory responses to hypercapnic acidosis in channel catfish. Comp Biochem Physiol A Physiol 125: 403-414, 2000.

6. Davison W, Axelsson M, Nilsson S, and Forster ME. Cardiovascular control in Antarctic notothenioid fishes. Comp Biochem Physiol A Physiol 118: 1001-1008, 1997.

7. Egginton S. A comparison of the response to induced exercise in red- and white-blooded Antarctic fishes. J Comp Physiol [B] 167: 129-134, 1997.

8. Egginton S. Control of tissue blood flow at very low temperatures. J Therm Biol 22: 403-407, 1997.

9. Egginton $\mathbf{S}$ and Davison W. Effects of environmental and experimental stress on Antarctic fish. In: Cold Ocean Physiology, edited by Pörtner HO and Playle RC. NY: Cambridge University Press, 1998. p. 299-326.

10. Fanta E, Lucchiari PH, and Bacila M. The effect of environmental oxygen and carbon dioxide levels on the tissue oxygenation and the behavior of Antarctic fish. Comp Biochem Physiol 93A: 819-831, 1989.

11. Frederich M and Pörtner HO. Oxygen limitation of thermal tolerance defined by cardiac and ventilatory performance in spider crab, Maja squinado. Am J Physiol Regul Integr Comp Physiol 279: R1531-R1538, 2000.

12. Furimsky M, Moon TW, and Perry SF. Evidence for the role of a $\mathrm{Na}^{+} / \mathrm{HCO}_{3}{ }^{-}$cotransporter in trout hepatocyte $\mathrm{pH}_{i}$ regulation. J Exp Biol 203: 2201-2208, 2000.

13. Gille ST. Warming of the Southern Ocean since the 1950s. Science 295: 1275-1277, 2002.

14. Gilmour KM and Perry SF. The effects of hypoxia, hyperoxia or hypercapnia on the acid-base disequilibrium in the arterial blood of rainbow trout. J Exp Biol 192: 269-284, 1994.

15. Hardewig I, Peck LS, and Pörtner HO. Thermal sensitivity of mitochondrial function in the Antarctic notothenioid lepidonotothen nudifrons. J Comp Physiol [B] 169: 597-604, 1999.

16. Heisler N, Toews DP, and Holeton GF. Regulation of ventilation and acid-base status in the elasmobranch Scyliorhinus stellaris during hyperoxia-induced hypercapnia. Respir Physiol 71: 227-246, 1988 .

17. Hyder F, Kida I, Behar KL, Kennan RP, Maciejewski PK, and Rothman DL. Quantitative functional imaging of the brain: towards mapping neuronal activity by BOLD fMRI. NMR Biomed 14: 413-431, 2001.

18. Johnston IA and Dunn J. Temperature acclimation and metabolism in ectotherms with particular reference to teleost fish. In: Temperature and Animal Cells, edited by Bowler K, Fuller BJ. Cambridge, UK: Company of Biologists Limited, 1987, p. 67-93.

19. Jones DR. Theoretical analysis of factors which may limit the maximum oxygen uptake of fish: the oxygen cost of the cardiac and branchial pumps. J Theor Biol 32: 341-349, 1971.

20. Kennan RP, Scanley BE, and Gore JC. Physiologic basis for BOLD MR signal changes due to hypoxia/hyperoxia: separation of blood volume and magnetic susceptibility effects. Magn Reson Med 37: 953-956, 1997.
21. Kerskens CM, Hoehn-Berlage M, Schmitz B, Busch E, Bock C, Gyngell ML, and Hossmann KA. Ultrafast perfusionweighted MRI of functional brain activation in rats during forepaw stimulation: comparison with $\mathrm{T}_{2}{ }^{*}$-weighted MRI. NMR Biomed 9: 20-23, 1996.

22. Kim SG, Hendrich $\mathbf{K}$, Hu X, Merkle $H$, and Ugurbil $\mathbf{K}$. Potential pitfalls of functional MRI using conventional gradientrecalled echo techniques. NMR Biomed 7: 69-74, 1994.

23. Lebon V, Brillault-Salvat C, Bloch G, Leroy-Willig A, and Carlier PG. Evidence of muscle BOLD effect revealed by simultaneous interleaved gradient-echo NMRI and myoglobin NMRS during leg ischemia. Magn Reson Med 40: 551-558, 1998.

24. Levin JM, Frederick B, Ross MH, Fox JF, von Rosenberg HL, Kaufman MJ, Lange N, Mendelson JH, Cohen BM, and Renshaw PF. Influence of baseline hematocrit and hemodilution on BOLD fMRI activation. Magn Reson Imaging 19: 10551062, 2001.

25. Mansfield $\mathbf{P}$ and Morris PG. NMR imaging in biomedicine. In: Advances in Magnetic Resonance, edited by Waugh JS. London: Academic, 1982.

26. Moerland TS and Egginton S. Intracellular $\mathrm{pH}$ of muscle and temperature: insight from in vivo ${ }^{31} \mathrm{P}$ NMR measurements in a stenothermal Antarctic teleost (Harpagifer antarcticus). $J$ Therm Biol 23: 275-282, 1998.

27. Ogawa S, Lee TM, Kay AR, and Tank DW. Brain magnetic resonance imaging with contrast dependent on blood oxygenation. Proc Natl Acad Sci USA 87: 9868-9872, 1990.

28. Oikawa H, al-Hallaq HA, Lewis MZ, River JN, Kovar DA, and Karczmar GS. Spectroscopic imaging of the water resonance with short repetition time to study tumor response to hyperoxia. Magn Reson Med 38: 27-32, 1997.

29. Pörtner HO. Climate change and temperature-dependent biogeography: oxygen limitation of thermal tolerance in animals. Naturwissenschaften 88: 137-146, 2001.

30. Pörtner HO. Climate variations and the physiological basis of temperature dependent biogeography: systemic to molecular hierarchy of thermal tolerance in animals. Comp Biochem Physiol A Physiol 132: 739-761, 2002.

31. Pörtner HO, Berdal B, Blust R, Brix O, Colosimo A, De Wachter B, Giuliani A, Johansen T, Fischer T, Knust R, Naevdal G, Nedenes A, Nyhammer G, Sartoris FJ, Serendero I, Sirabella P, Thorkildsen S, and Zakhartsev $M$. Climate induced temperature effects on growth performance, fecundity and recruitment in marine fish: developing a hypothesis for cause and effect relationships in Atlantic cod (Gadus morhua) and common eelpout (Zoarces viviparus). Cont Shelf Res 21: 1975-1997, 2001.

32. Pörtner HO, Boutilier RG, Tang Y, and Toews DP. Determination of intracellular $\mathrm{pH}$ and $\mathrm{PCO}_{2}$ after metabolic inhibition by fluoride and nitrilotriacetic acid. Respir Physiol 81: 255-274, 1990.

33. Pörtner HO, Hardewig I, and Peck LS. Mitochondrial function and critical temperature in the Antarctic bivalve, Laternula elliptica. Comp Biochem Physiol A Physiol 124: 179-189, 1999.

34. Pörtner HO, van Dijk PLM, Hardewig I, and Sommer A. Levels of metabolic cold adaptation: tradeoffs in eurythermal and stenothermal ectotherms. In: Antarctic Ecosystems: Models for a Wider Understanding, edited by Davison W and Williams CW. Christchurch, New Zealand: Caxton, 2000, p. 109-122.

35. Rausch RN, Crawshaw LI, and Wallace HL. Effects of hypoxia, anoxia, and endogenous ethanol on thermoregulation in goldfish, Carassius auratus. Am J Physiol Regul Integr Comp Physiol 278: R545-R555, 2000.

36. Reeves RB. An imidazole alphastat hypothesis for vertebrate acid-base regulation: tissue carbon dioxide content and body temperature in bullfrogs. Respir Physiol 14: 219-236, 1972.

37. Reeves RB. Alphastat regulation of intracellular acid-base state? In: Circulation, Respiration and Metabolism, edited by Gilles R. Heidelberg: Springer Verlag, 1985, p. 414-423.

38. Rolett EL, Azzawi A, Liu KJ, Yongbi MN, Swartz HM, and Dunn JF. Critical oxygen tension in rat brain: a combined ${ }^{31} \mathrm{P}-\mathrm{NMR}$ and EPR oximetry study. Am $J$ Physiol Regul Integr Comp Physiol 279: R9-R16, 2000. 
39. Saint-Paul U. Diurnal routine $\mathrm{O}_{2}$-consumption at different $\mathrm{O}_{2}$ concentration by Colossoma macropomum and Colossoma brachypomum (Teleostei: Serrasalmidae). Comp Biochem Physiol 89A: 675-682, 1988.

40. Semple SIK, Wallis F, Haggarty P, Abramovich D, Ross JAS, Redpath TW, and Gilbert FJ. The measurement of fetal liver $\mathrm{T}_{2} *$ in utero before and after maternal oxygen breathing: progress towards a non-invasive measurement of fetal oxygenation and placental function. Magn Reson Imaging 19: 921-928, 2001.

41. Shelford VE. Some concepts of bioecology. Ecology 12: 455-467, 1931.

42. Sidell BD. Physiological roles of high lipid content in tissues of Antarctic fish species. In: Biology of Antarctic Fish, edited by di Prisco G, Maresca B, and Tota, B. Berlin: Springer Verlag, 1991, p. 221-231.

43. Sidell BD. Intracellular oxygen diffusion: the roles of myoglobin and lipid at cold body temperature. J Exp Biol 201: 1118-1127, 1998.

44. Somero GN and DeVries AL. Temperature tolerance of some Antarctic fishes. Science 156: 257-258, 1967.

45. Sommer A, Klein B, and Pörtner HO. Temperature induced anaerobiosis in two populations of the polychaete worm Arenicola marina (L). J Comp Physiol [B] 167: 25-35, 1997.

46. Soncini R and Glass ML. The effects of temperature and hyperoxia on arterial $\mathrm{PO}_{2}$ and acid-base status in Piaractus mesopotamicus. J Fish Biol 51: 225-233, 1997.

47. Southward AJ. Note on the temperature tolerances of some intertidal animals in relation to environmental temperatures and geographical distribution. J Mar Biol Ass UK 37: 49-66, 1958.
48. Takeda T. Ventilation, cardiac output and blood respiratory parameters in the carp, Cyprinus carpio, during hyperoxia. Respir Physiol 81: 227-240, 1990.

49. Taylor CR and Weibel ER. Design of the mammalian respiratory system. I: Problem and strategy. Respir Physiol 44: 1-10, 1981.

50. Van Dijk PLM, Tesch C, Hardewig I, and Pörtner HO. Physiological disturbances at critically high temperatures: a comparison between stenothermal Antarctic and eurythermal temperate eelpouts (Zoarcidae). J Exp Biol 202: 3611-3621, 1999.

51. Van Ginneken V, van den Thillart G, Addink A, and Erkelens C. Synergistic effect of acidification and hypoxia: in vivo ${ }^{31} \mathrm{P}-\mathrm{NMR}$ and respirometric study in fishes. Am J Physiol Regul Integr Comp Physiol 271: R1746-R1752, 1996.

52. Weatherley AH. Effects of superabundant oxygen on thermal tolerance of goldfish. Biol Bull 139: 229-238, 1970.

53. Wells RMG. Cutaneous oxygen uptake in the Antarctic icequab, Rhigophila dearborni (Pisces: Zoarcidae). Polar Biol 5: 175-179, 1986.

54. Wells RMG and Jokumsen A. Oxygen binding of hemoglobins from Antarctic fishes. Comp Biochem Physiol 71B: 469-473, 1982.

55. Wohlschlag DE. An Antarctic fish with unusually low metabolism. Ecology 44: 557-564, 1963.

56. Wood CM and Jackson EB. Blood acid-base regulation during environmental hyperoxia in the rainbow trout (Salmo gairdneri). Respir Physiol 42: 351-372, 1980.

57. Zielinski $\mathbf{S}$ and Pörtner HO. Energy metabolism and ATP free-energy change of the intertidal worm Sipunculus nudus below a critical temperature. J Comp Physiol [B] 166: 492-500, 1996.

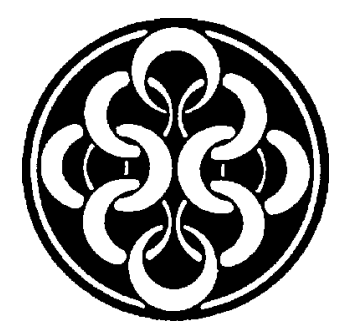

